\title{
Making tools and making sense: complex, intentional behaviour in human evolution
}

\author{
Dietrich Stout and Thierry Chaminade
}

\begin{abstract}
Stone tool-making is an ancient and prototypically human skill characterized by multiple levels of intentional organization. In a formal sense, it displays surprising similarities to the multi-level organization of human language. Recent functional brain imaging studies of stone tool-making similarly demonstrate overlap with neural circuits involved in language processing. These observations consistent with the hypothesis that language and tool-making share key requirements for the construction of hierarchically structured action sequences and evolved together in a mutually reinforcing way.
\end{abstract}

\section{Introduction}

Although it may appear esoteric in the modern world, stone tool-making has been practiced in one form or another by virtually every human society for the past 2.5 million years. 2.6-million-year-old stone artefacts from Ethiopia (Semaw et al. 1997, Semaw et al. 2003) provide the earliest evidence of uniquely hominin tool-making capabilities and exemplify a basic human technology that remained widespread until the recent past, and in some cases endured into the modern era (Roux, Bril, and Dietrich 1995, Skertchly 1984, Stout 2002, Weedman 2000). In fact, stone toolmaking is a prototypical human skill integrating demands for planning, problemsolving and perceptual-motor coordination within a pragmatic, collaborative context. Together with its likely evolutionary importance, this makes stone tool-making an important object of study for cognitive neuroscience as well as archaeology.

The Early Stone Age (ESA) alone encompasses roughly $90 \%(2.6-0.25 \mathrm{Ma})$ of human prehistory and charts a technological progression from simple Oldowan stone chips to large, skilfully shaped Acheulean cutting tools. During this period hominin brain size nearly tripled, from the high end of the chimpanzee range to the low end of the modern human range. It is reasonable to conjecture that many distinctive aspects of modern human brain structure and function evolved during this period of massive brain expansion. More controversial is the role changing lithic technologies may have played as cause, consequence or correlate to hominin brain and cognitive evolution (e.g. Ambrose 2001, Deacon 1997, Gibson and Ingold 1993, Mithen 1996, Nobel and Davidson 1996, Roux and Bril 2005, Wynn 2002, Wynn and McGrew 1989).

Of particular interest have been possible relations between language, gesture and tool-use in human evolution. Such relations have received renewed attention in recent years as a result of research into motor resonance, the tendency for neural structures involved in action execution to also be recruited during action observation. This is thought to provide a direct mechanism for understanding the intentions and goals of others through what amounts to a kind of motor "empathy". Mirror-neurons found in 
a putative Broca's area homolog (ventral premotor area F5) in monkeys (Rizzolatti and Craighero 2004) provide a specific demonstration of resonance at the cellular level and have inspired recent hypotheses for the evolution of articulate language through intermediate stages of imitation, pantomime and "protosign" language (Arbib 2005, Rizzolatti and Arbib 1998). Many other such scenarios and mechanisms for the co-evolution of language and tool-making have been proposed over the years.

A number of researchers have argued that language and tool-making share underlying cognitive and neural requirements for hierarchically structured action sequencing (Greenfield 1991, Holloway 1969). This is consistent with broader motor hypotheses of language origins, which derive key language properties from the multilevel motor coordination required in speech (Liberman and Whalen 2000, MacNeilage 1998, Studdert-Kennedy and Goldstein 2003) and/or cerebral asymmetries in manual and vocal control (Corballis 2003, MacNeilage, StuddertKennedy, and Lindblom 1984). Another, less direct, strand of argumentation has been to emphasise the selective pressures for intentional communication arising from collaborative technological activities (Engels 2003, Reynolds 1993) and pedagogy (Greenfield 1998, Stout 2002).

Palaeolithic stone artefacts provide a unique source of behavioural, chronological and contextual evidence that may be used to constrain such evolutionary hypotheses (Wynn 2002). The availability of this evidence is largely due to the durability of stone artefacts, however putative links between stone tools and language are more than just a matter of convenience for archaeologists. The hand and mouth are the two most complex and flexible effectors of the human body and are regulated by neighbouring or even partially overlapping neural circuits. This is particularly notable in the case of object manipulation (Hamzei et al. 2003). These cortical circuits include regions of inferior frontal and parieto-temporal association cortex connected by the arcuate fasciculus (Figure 1), all of which have been disproportionately expanded (Rilling 2006, Rilling et al. 2008) in the massive cortical growth that began soon after the appearance of the first stone tools.

Bipedal locomotion, another distinctive human characteristic, has been hypothetically linked to the evolution of basal ganglia circuits important to language (Lieberman 2002) but does not appear to overlap with cortical language circuits (Santi et al. 2003). Furthermore, bipedalism predates significant brain expansion by at least 1.5 million years, was associated with an ape-like vocal tract including laryngeal airsacs (Alemseged et al. 2006), and shows little of the higher-level intentional organization seen in both language and tool-making. Even if bipedalism did promote early preadaptations for speech, it is unlikely to be directly relevant to major subsequent developments. Other putative hominin behaviours such as hunting or social strategizing are complex and cognitively demanding, but do not share demands for the rapid sequencing of complex motor gestures seen in language and toolmaking. Lithic and other less archaeologically visible technologies (e.g. Mazza et al. 2006, Thieme 1997) involving manual object manipulation thus continue to provide the closest correspondence with language, and are the most likely candidates for hypothetical co-evolutionary relationships.

Until recently, however, empirical evidence of the specific neural and cognitive substrates of particular ancient technologies has been lacking. In an attempt to address this problem, we have recently undertaken a series of functional brain imaging investigations of ESA tool-making (Stout and Chaminade 2007, Stout et al. 2000, Stout et al. 2008). By comparing tool-making with a baseline manipulative task we sought to isolate the distinctive neural demands of ESA technologies. Among other 
things, this provided evidence of specific points of overlap with cortical language circuits. Here we present a more extended discussion of the theoretical and evolutionary implications of these findings.

\section{Neurobehavioural foundations of articulate language and manual action}

Quite some time ago, Holloway (1969) pointed out that any motor act can be described as a hierarchically structured sequence of behavioural "units". For Holloway, the more interesting question was whether there is any meaningful correspondence between specific "units" of speech and stone tool-making. Or, as Arbib (2006) more recently asked, "a sentence is to speech as what is to action?". Functional brain imaging results suggest that meaningful correspondences do exist between language and ESA tool-making, and furthermore that that these correspondences are to be found at increasingly higher levels of organization in more sophisticated stone technologies.

Articulate language involves the combination of units on at least three nested levels, loosely described as sound combinations (phonology), word combinations (syntax), and conceptual combinations (semantics). Those of an anthropological bent might wish to distinguish a fourth level of more extended conceptual combinations in discourse semantics (Rose 2006). These levels correspond to intervals on increasing scales of temporal duration and hierarchical abstraction.

Patterns of brain activation associated with particular linguistic tasks similarly vary according to scale. This probably reflects general organizational properties of the cerebral cortex (Deacon 1997, Fuster 2001) rather than anything special to language. For example, cortical fields with relatively direct connections to the rest of the body (e.g. primary and secondary sensorimotor areas) generally tend to be involved in rapid processing whereas those increasingly dominated by intracortical connections (association areas) are involved in larger-scale integration across time. There is also good evidence of hemispheric differences in the scale of processing, with the left hemisphere (LH) apparently specializing in small-scale rapid processing and the right hemisphere $(\mathrm{RH})$ specializing in larger scale and longer duration processing (Deacon 1997). This trend is evident across linguistic (Bookheimer 2002, Poeppel 2003), perceptual (Gazzaniga 2000), and cognitive (Gazzaniga 2000, Goel et al. 2007) domains.

The neural bases of manual action reflect many of these same scale-related organizing principles, as well as some points of more specific overlap with systems involved in articulated language. This is particularly evident in inferior lateral frontal cortex, which displays a clear posterior to anterior gradient of increasing processing scale and abstraction (Fiebach and Schubotz 2006, Hagoort 2005, Koechlin and Jubault 2006). This region includes (from back to front) orofacial and manual motor cortex, ventral premotor cortex, and distinct posterior and anterior potions of Broca's area (Figure 1). All of these appear to play an important role in both articulate language and manual action.

\section{Ventral premotor cortex: phonology and prehension}

Many hypotheses of language origins have emphasised the importance of enhanced human articulatory control (e.g. Deacon 1997, Liberman and Whalen 2000, Lieberman 2002, MacNeilage 1995, Studdert-Kennedy and Goldstein 2003). This control would appear to arise from increased cortical regulation of the vocal apparatus, and particularly from the contributions of a left hemisphere circuit linking the superior temporal gyrus (Hickok et al. 2000) with portions of frontal lobe ventral 
premotor cortex (PMv) and the adjoining orofacial motor cortex. PMv likely plays an important role in phonological processing (Bookheimer 2002, Hagoort 2005) by combining phonological elements from the superior temporal gyrus into intonational phases.

$\mathrm{PMv}$ is thought to play a closely analogous role in the combination of manual grasp elements (e.g. flexion, rotation) provided by parietal lobe association cortex during object prehension (Fagg and Arbib 1998). In fact, PMv participates in multiple neural circuits supporting sensorimotor transformations for action across a variety of modalities. Macaque PMv, for example, displays overlapping responsiveness to visual, tactile and auditory stimuli (Graziano, Reiss, and Gross 1999), and has recently been found to co-activate with temporal lobe auditory cortex (specifically a putative Wernicke's area homologue) in the perception of species-specific calls (Gilda-Costa et al. 2006). In humans, PMv is divided into inferior and superior fields which are responsive to auditory and visual stimuli respectively (Schubotz and von Cramon 2003). This division, which mirrors the superior/inferior organization of hand and orofacial regions in adjacent primary motor cortex, is also evident during action observation, with the superior PMv field responding to observed hand actions and the inferior portion to observed mouth actions (Buccino et al. 2001). Kinematic studies reveal that grasping movements with the hand affect concurrent movements of the mouth, with larger manual target objects being associated with wider, faster opening of the mouth and with increased power of the voice spectrum during syllable pronunciation (Gentilucci et al. 2001). PMv has thus been characterized as producing an "action vocabulary" across a wide array of different behaviours, reflecting a more general role in processing sequentially structured events (Schubotz and von Cramon 2004).

PMv activity has been described as characteristically goal-oriented (Rizzolatti et al. 1988, Schubotz and von Cramon 2004, van Schie, Toni, and Bekkering 2006). PMv neurons are "tuned" to specific goals like grasping, placing or holding an object and are less responsive to either discrete action elements (e.g. finger flexion) or larger action composites (e.g. eating a peanut). Individual PMv neurons also display a temporal tuning to particular portions of these goal-directed actions, such as hand opening or closure. These response characteristics indicate the role of PMv in combining discrete gestural elements into simple goal directed actions, much as syllables are produced from coordinated patterns of articulatory "gestures" by the tongue, lips, velum and so forth (Studdert-Kennedy and Goldstein 2003).

Overlapping PMv contributions to phonological processing and object manipulation provide evidence of a specific neurobehavioral correspondence between language and manual action involving this region. In particular, this correspondence is found at the level where discrete articulatory and prehensile elements are assembled into short goal directed action units, such as grasping an object or pronouncing an intonational phrase.

\section{Posterior Broca's area: syntax and action sequencing}

Anterior to PMv in inferior prefrontal cortex is Broca's area, classically associated with fluent speech production. A more current view sees Broca's area as multifunctional, involved in both linguistic and non-linguistic behaviors, and encompassing a posterior-anterior gradient from phonology to syntax to semantics (Hagoort 2005). The more posterior portion of Broca's area (Brodmann Area [BA] 44 ) is preferentially recruited during syntactical processing (Bookheimer 2002) and appears to support the combination of lexical elements at the sentence level. Loosely, 
this level of syntactical organization reflects aspects of word order and phrase structure that may or may not affect meaning, as in "The woman lit the match that started the fire" vs. "The match that the woman lit started the fire."

Posterior Broca's area is also active during the observation and execution of objectdirected actions (Hamzei et al. 2003), and is specifically involved in the processing of simple action chunks. Koechlin and Jubault (2006) were able to characterize this functional contribution of Broca's area using a hierarchically structured sequential button pressing task. This task included "simple chunks" consisting of pre-learned button press sequences as well as "superordinate chunks" in which the rules governing button selection changed according to a pre-learned sequence. Results showed a clear posterior-anterior gradient, with PMv active between single acts, posterior Broca's area active during transitions between simple chunks, and anterior Broca's area active between superordinate chunks. This led Koechlin and Jubault (p. 968) to conclude that "posterior [Broca's area] regions are involved in selecting and inhibiting simple action chunks in response to external signals or as successive components of ongoing superordinate actions." Applied to lexical elements, this would also be a reasonable description of the role of posterior Broca's area in language processing, suggesting a further correspondence between language and manual action at the level of syntax and action sequencing.

\section{Anterior Broca's area: semantics and meaningful action}

Anterior Broca's area (here including BA 45 and 47) is involved in semantic unification (Hagoort et al. 2004). An example of such unification is the clarification of ambiguous word meanings in relation to broader world knowledge and sentence context. This requires increased hierarchical abstraction of the kind attributed to anterior Broca's area by Koechlin and Jubault (2006) as well as the ability to integrate information over a relatively extended temporal frame. Both characteristics fit well with the general trend toward more abstract, integrative, longer-duration and modality-independent processing in more anterior prefrontal cortex (Deacon 1997, Petrides 2005). The selective involvement of anterior Broca's area in the semantic processing of words and sentences is well attested in the neuroimaging literature (Bookheimer 2002, Martin and Chao 2001), and likely reflects an underlying role in the retrieval and selection between semantic representations (Kan et al. 2006, Martin 2003).

Anterior Broca's area is similarly involved in non-linguistic action semantics. For example, the more caudal portion (BA 45) is preferentially recruited during the observation of meaningful actions (like opening a bottle or hammering a nail) as opposed to meaningless hand motions (Decety et al. 1997). The more rostral BA 47 has been implicated in numerous higher-order aspects of action organization, including task switching, reversal learning and the selection, comparison and evaluation of stimuli held in memory (Ramnani and Owen 2004), which are critical to the production of complex, flexible and goal-oriented behaviours. This indicates a third correspondence between language and manual action at the level of semantics and meaningful action.

\section{Right cerebral hemisphere: Discourse and complex, multi-step action}

Further increases in temporal scale to the level of discourse are associated with increased involvement of the right cerebral hemisphere. Although the left hemisphere (LH) has classically been viewed as the "language hemisphere" it is now clear that this is an oversimplification. In fact, both hemispheres are commonly activated in 
speech perception (Poeppel 2003), and the right hemisphere (RH) is known to play an important role in larger-scale elements of language, including metaphor, figurative language, connotative meaning, prosody, and discourse comprehension (Bookheimer 2002, Xu et al. 2005).

Bilateral activation is also present in Broca's area and its RH homolog during hierarchically structured manual action (Koechlin and Jubault 2006). Although there is some evidence of a left-lateralized system involved in planning single actions with everyday tools (Johnson-Frey, Newman-Norlund, and Grafton 2005), the actual use of tools tends to produce a less pronounced LH dominance (Lewis 2006). When it comes to assembling more protracted action sequences, RH plays a key role. For example, Frey and Gerry (2006) found that RH and not LH activation was correlated with success in imitating the specific sequence of actions used in assembling a tinkertoy. Hartmann and colleagues (2005) similarly found that, although patients suffering RH brain damage are typically unimpaired in the single-action use of familiar tools, they are impaired when it comes to executing multi-step, naturalistic actions like making a cup of coffee. This suggests a final correspondence between language and manual action at the level of pragmatic discourse and complex, multi-step action.

\section{Making sense: meaning in language and tool-making}

The preceding survey highlights the facts that (1) language is not a single "thing" but rather a complex phenomenon involving multiple interacting systems and levels of organization, and (2) the particular neural substrates of language reflect more general trends of brain organization and overlap extensively with other forms of intentional action. This is consistent with the view that language is a complex learned behaviour mapped onto relevant brain systems, rather than the product of invariant, genetically specified "language circuits"(Deacon 1997). Similarities in the hierarchical processing requirements of language and manual action result in neural overlap on a variety of levels.

The particular points of overlap described above support and refine the early work of Holloway (1969) who proposed that stone tool-making, like language, involves "phonemic", "grammatical" and "semantic" levels of organization. Holloway suggested that the phonemic level might include actions like striking a flake or rotating the core, that the grammar is a concatenation of these elements, and that the semantics are to be found in the intended purpose individual actions and finished tools. The more recent evidence discussed above suggests that the "phonemic" units should probably be smaller (e.g. hand configurations, arm movements) than those envisioned by Holloway, with relatively straight forward knock-on effects on the scale of the rest of the scheme. One key point that does require further consideration, however, is the concept of tool-making "semantics".

The issue of meaning is central to Holloway's broader argument about the uniqueness of human culture, which he identifies with "the imposition of arbitrary form on the environment". Ingold (1996) has similarly argued that human uniqueness resides in "the self-conscious authorship of design" and the projection of symbolic meaning onto the environment. Symbolic meaning is obviously a key feature of human language and culture, but in what sense might it be evident in stone toolmaking?

As Deacon $(1997,2003)$ has explained, symbolic reference is itself constructed in a hierarchical fashion from underlying iconic and indexical relationships. Iconicity, rooted in physical similarity, is the basis for recognizing different instances of a behaviour (e.g. vocal utterances, hand postures) as the same "thing". Indexicality is 
then based on correlation (causal or arbitrary) between iconically related classes of stimuli, for example smoke and fire, food and a bell, or the word "apple" and an apple. Symbolic reference lies on the next level of the hierarchy as a relationship between indices. More precisely, the referential power of a symbol comes from "its position within a structured set of indexical relationships among symbol tokens" (Deacon 2003: 122). For example, the symbolic meaning of "apple" comes from a superordinate system of indexical associations with other words like "fruit", "sweet" or "computer" as well as from immediate context. This is why dictionaries define word meaning by providing systematic mappings of each word onto others.

In stone tool-making, one might similarly say that the meaning of an action comes from its possible associations with other actions in a superordinate system of technological rules. The closest correspondence with word meaning is probably at the level of relations between individual goal-oriented actions, as in striking a flake as part of a planned reduction sequence. The meaning of this action is constructed by recognizing iconic stimulus classes (grips, gestures, outcomes), their indexical (cause and effect) relation to each other, and finally the possible relationship of these indexical relationships to each other in achieving a technological goal. The hierarchical structure involved is thus formally similar to that used in constructing symbolic reference. But is meaning in the sense of the goal-oriented intention of an action really comparable to symbolic meaning? This depends on what it actually means for a tool-making act to be "intentional".

"Intentional" is a word used in multiple ways. In everyday speech it typically means "deliberate" or "on purpose". For philosophers it has come to have a more specialized meaning, denoting "aboutness" (Dennett and Haugeland 1987) or the property of referring to or being directed at something (the "intentional object"). In both colloquial and technical senses "intention" is about meaning, be it the meaning of an action (Did you intend to do that?) or the meaning of a symbol (Do you mean 'an apple', 'the apple of my eye', or 'Apple Computers'?). In each case meaning is dependant on context and exists on multiple levels (Searle 1992). For example, a stone tool-maker might simultaneously intend to move his arm, to detach a flake, to modify a bifacial edge, to shape a handaxe, to disarticulate a carcass, and to increase his prestige through a display of skill, depending on the level of description (Keijzer 1998, Stout 2002). Similarly, it is part of the power of language that "I hear you" can be a statement of fact, an indication of agreement, and a gesture of support, all at the same time. The true "meaning" of this statement has to do with the level of discourse one attends to.

This highlights the fact that speech is itself a form of action (Austin 1975) used to enact relations and construe experience (Rose 2006). Internal cogitation, often including sub-vocal speech, is also typically aimed at construing experience in one way or another. Even such apparently abstract intentional phenomena as hopes and beliefs may be seen as concrete reactions to the world, with meanings defined in relation to our goals (e.g. seeking gratification, understanding our surroundings). On this view, intentionality is a property of goal-directed interactions between agent and environment. From this it follows that the "level" at which we find intentionality is closely related to the behavioural competence of the agent:

Thus, for example, the beginning skier may require an intention to put the weight on the downhill ski, an intermediate skier has the skill that enables him to have the intention to "turn left," a really expert skier may simply have the intention to "ski this slope"...Similarly, when I am speaking English, I do not have the intention to 
match singular nouns with singular verbs or plural nouns with plural verbs - I just talk. (Searle 1992 pp. 195)

Depending on the social and linguistic aptitude of the speaker, "just talking" might similarly contribute to a range of higher-order intentions. For example, the exaggerated intonational contours and repetition typical of infant directed speech ("motherese") may serve to facilitate word segmentation and phoneme recognition during language acquisition (Falk 2004). Similarly, in stone tool-making the intentional exaggeration of certain actions for the benefit of observers might serve a pedagogical purpose. Together with other forms of intentional instruction and collaborative technological action, such demonstration would provide a context for the transition from imitation to intentional communication without the need for an intermediate 'protosign' stage (contra Arbib 2005).

\section{Early Stone Age tool-making and language evolution}

ESA knapping methods include Mode I (Clark 1961) flake production and Mode II bifacial shaping. Mode I flaking is characteristic of the Oldowan Industrial Complex (Isaac 1976), which is currently known from $2.6 \sim 1.4 \mathrm{Ma}$ (although examples of this simplest of knapping methods may be found throughout prehistory). The method involves the production of sharp-edged flakes by striking one stone (the core) with another (the hammerstone). Mode II knapping, which requires the deliberate shaping of the core to achieve a pre-determined form, first appears after $\sim 1.7 \mathrm{Ma}$ and characterizes the Acheulean Industrial Complex (Clark 1994). The prototypical Acheulean artefact is the so-called "handaxe", a more-or-less symmetrical, teardrop-shaped tool systematically worked on both faces and wellsuited for butchery and other heavy duty cutting tasks (Schick and Toth 1993). The archaeologically documented progression from Mode I to Mode II tool-making provides direct evidence of increasing hierarchical complexity in at least one sphere of early hominin behaviour, as well as indirect evidence of increasingly effective mechanisms for the social reproduction of technological skills.

\section{Mode I tool-making and PMv expansion}

Effective Mode I flake detachment requires visuomotor coordination and evaluation of three-dimensional core morphology (Stout and Chaminade 2007) so that forceful blows may reliably be directed to appropriate targets. In addition to sophisticated visual perception, this requires speed and accuracy (Stout 2002) of the right ${ }^{1}$ hand in delivering blows and the use of effective grips (Marzke et al. 1998) by both hands so that the stones may be properly stabilized and oriented with points of impact exposed. Detailed evidence of the complex and demanding motor synergies of the right limb involved in effective percussion comes from experimental studies of traditional stone bead knappers in India (Biryukova et al. 2005, Roux, Bril, and Dietrich 1995). Modern knappers engaged in freehand percussion (the most likely posture for Oldowan knapping) further report that the fingertips of the left hand, positioned directly below the point of impact, can serve as a proprioceptive guide to percussion (Stout 2002) and exert pressure that may help to guide flake detachment (Jones 1994).

\footnotetext{
${ }^{1}$ For simplicity, and because all subjects in the experiments discussed here were right-handed, "right hand" and "left hemisphere" will be used to refer to the "dominant" side. This also avoids some misleading terminology, in that hands and hemispheres are best seen as specialized for different tasks rather than simply being "dominant" or "non-dominant".
} 
Brain activation during Mode I knapping (Stout and Chaminade 2007, Stout et al. 2008) reflects these visuomotor challenges, including visual shape perception and manual grip coordination. Of particular interest is activation of an object prehension circuit linking the anterior intraparietal sulcus (IPS) and ventral premotor cortex (PMv). As described above, this circuit is thought to support the combination of grasp elements into an "action vocabulary", much as a parallel circuit connecting superior temporal gyrus to PMv is thought to support the combination of phonological into intonational phases.

This is broadly consistent with the evolutionary-developmental hypothesis of Greenfield (1991), who proposed that discrete manual and linguistic circuits in the posterior inferior frontal lobe emerge through postnatal developmental differentiation of a common neural substrate. Such differentiation is thought to result from the exuberant growth and subsequent pruning of synaptic connections, driven by neuronal competition, intrinsic gene expression gradients, and extrinsic stimuli. This is a plastic process, even into adulthood (Hihara et al. 2006), and it is quite plausible that PMv expansion related to selection for manipulative functions could have provided an exaptive foundation for the evolution of neighbouring articulatory circuits.

Evidence of preferential PMv recruitment during Mode I tool-making by modern humans (Stout and Chaminade 2007, Stout et al. 2008) strongly suggests that comparable tool-making by Oldowan hominins also involved similarly distinctive demands on the primitive (Rizzolatti, Luppino, and Matelli 1998) manipulative functions of this region. Expansion of PMv would be one possible outcome of selection acting on these functions and, in fact, premotor cortex as a whole does seem to be expanded in humans (Blinkov and Glezer 1968), though not to the same extent as prefrontal and temporo-parietal association cortices (Deacon 1997, Rilling 2006). The appearance of Oldowan tools 2.6 million years ago provides evidence of novel demands and capabilities for action organization in this region, and may have contributed to the evolution of the neural substrates of articulate language. This scenario differs from Greenfield's (1991) proposal in that it deals with articulatory and manual coordination in PMv rather than word and object combination in Broca's area, and by virtue of its specific link to the archaeological record. However the proposals are not mutually exclusive and the underlying evolutionary logic is the same.

\section{Mode II tool-making and anterior Broca's area}

Although initially quite crude, by the later ESA ( $<0.5$ million years ago) many handaxes achieved a level of refinement indicative of advanced tool-making skills (Edwards 2001) and possibly of aesthetic concerns beyond the purely utilitarian (Machin, Hosfield, and Mithen 2007). In comparison to Mode I tool-making, the production of such tools involves increased demands for hierarchical action organization and fine bimanual coordination. In the brain, this is associated with additional activation of the RH homolog of anterior Broca's area (Stout et al. 2008).

As described elsewhere (Stout, Toth, and Schick 2006, Stout et al. 2008), the additional demands of Mode II tool-making have a lot to do with the need to strike highly invasive "thinning flakes" that travel at least half way across the surface of the piece. This is accomplished through careful platform preparation, often using a different hammerstone and following very different technical rules from primary flake detachment. Various different percussors and techniques may also be used to accomplish sub-goals such as bifacial edging, thinning and shaping. The production of a well-formed handaxe thus requires individual actions to be coordinated, not only 
with respect to the ultimate goal, but also in terms of various superordinate rule systems pertaining to different technical operations. This is analogous to the superordinate sequencing task of Koechlin and Jubault (2006), which also elicited (bilateral) anterior Broca's area activation. The activation of the RH Broca's homolog specifically by Mode II tool-making likely reflects the particularly critical role of the left hand in manipulating, orienting and supporting the core (Stout et al. 2008), and may also have to do with putative specializations of this region for response inhibition and task-set switching (Aron, Robbins, and Poldrack 2004).

Anterior Broca's area and RH contributions to higher-level aspects of language and multi-step action organization are described above. Activation of this region during Mode II tool-making by modern humans (Stout et al. 2008) provides direct evidence of the increased hierarchical complexity of the activity, and implies similar demands in comparable prehistoric (i.e. late Acheulean) technologies. While handaxe making does not provide direct evidence of language capacities, it does reflect the presence of hierarchical processing capabilities important to both activities. These may have been in place at an earlier date, but are first attested in the archaeological record by the appearance and subsequent refinement of Mode II tool-making. As was the case with PMv and Mode I tool-making, this neurobehavioral overlap is also consistent with the hypothetical co-evolution of linguistic and tool-making capabilities.

\section{Conclusion}

It is nothing new to propose an evolutionary link between language and toolmaking. In 1871, Darwin $(2004,69)$ himself argued that: "To chip a flint into the rudest tool...demands the use of a perfect hand...the structure of the hand in this respect may be compared with that of the vocal organs". In more recent years, however, many archaeologists have instead stressed the dissimilarities between language and stone tool-making (e.g. Chase 1991, Graves 1994, Mithen 1996, Nobel and Davidson 1996, Wynn 1995). Brain imaging studies of ESA tool-making (Stout and Chaminade 2007, Stout et al. 2008) provide important new empirical support for the early intuitions of Darwin, as well as for more recent proposals regarding the coevolution of language and technology.

The unique contribution of the imaging studies is to establish direct links between archaeologically visible behaviours and neural substrates. Results to date highlight the demands of manual grasp coordination in PMv during both Mode I and Mode II toolmaking and the increased prefrontal (anterior Broca's area) and RH demands of Mode II tool-making. The increasing sophistication of ESA tool-making seen through time thus documents the expression to increasingly complex capacities for hierarchical action organization. Furthermore, this progression closely parallels ascending phonetic, syntactical, semantic, and discourse levels of language processing in terms of both formal structure and neural organization. While stone tools still do not provide direct evidence of linguistic abilities, they do indicate the presence of analogous capacities in the realm of manual action organization (Holloway 1969). This is consistent with the hypothesis that selection acting on tool-making ability could have contributed to the evolution of language-relevant neural circuits (and vice versa) through a process of developmental displacement (Greenfield 1991).

Other recent hypotheses of language origins have focused on three key features: parity, recursion and symbolic reference. Parity is the requirement that sender and receiver attribute the same meaning to same elements of communicative behaviour. In other words, an iconic relationship must be established between actions which are the 
"same" whether produced by the self or perceived in another. In the realm of manual action this is thought to be achieved through the phenomenon of motor resonance, in which the same neural substrates are recruited during action observation as during action execution. Such resonant properties are evident in human premotor cortex, including but not limited to Broca's area. Mirror neurons found in the ventral premotor cortex (area F5) of monkeys offer one specific example of resonance and, although homologous neurons have not been observed in humans, have inspired hypothetical scenarios of language evolution in which manual imitation led to "protosign" language and eventually protospeech (Arbib 2005, Rizzolatti and Arbib 1998).

Preferential recruitment of PMv and the RH homolog of Broca's area during stone tool-making directly grounds such hypotheses in the known activities of early hominins. The close correspondence in the multi-level intentional structure of toolmaking and articulate language may even obviate the need for a transitional protosign stage, which has previously been proposed as a necessary bridge between imitation and intentional communication (Arbib 2005). Technological pedagogy and joint action provide equally plausible, archaeologically attested contexts for this transition without the need to posit an intermediate evolutionary stage with no modern analogue. A similar proposal was actually made by Friedrich Engels 125 years ago: "the development of labour necessarily helped to bring the members of society closer together by increasing cases of mutual support and joint activity, and by making clear the advantage of joint activity to each individual. In short, men in the making arrived at the point where they had something to say to each other." (2003: 73).

Parity may be a basic requirement for any communicative system, but it does not explain the great complexity and power of human language. This power is often attributed to the property of recursion or "discrete infinity" which allows discrete units to be combined and re-combined in a (theoretically) infinite series of nested layers. Recursion has been singled out by some as the core element of language unique to humans (Hauser, Chomsky, and Fitch 2002), but it is not clear that linguistic recursion is really so different from the hierarchy of behavioural chunks seen in stone tool-making or any other motor behaviour (Holloway 1969). What appears important is the level of abstraction at which recursion is employed.

Linguistic recursion is theoretically infinite, but in practice the use of more than a few embedded phrases tends to be very confusing for the listener. Similarly, one might imagine an arbitrarily complex series of nested operations in tool-making, although this does not occur in practice. Indeed, the observed neural overlap between Mode II tool-making and semantic language processing suggests that the degree of recursion involved may not be that different, at least in terms of how it is handled by the brain.

Much the same may be said of the relation of stone tool-making to symbolic reference. In both cases meaning is constructed in a hierarchical fashion from iconic and indexical relationships. The real question is whether the specific units of construction are in any way comparable. It has been argued that comparisons between symbolic reference and tool-making are misleading (Chase 1991, Graves 1994, Nobel and Davidson 1996, Wynn 1995), however the brain imaging evidence suggests that important overlap does exist. In the end, we may come to see language and toolmaking as alternate expressions of an underlying human capacity to make sense of the world in increasingly complex ways.

\section{References}


Alemseged, Z., F. Spoor, W. H. Kimbel, R. Bobe, D. Geraads, D. Reed \& J. G. Wynn, 2006. A juvenile early hominin skeleton from Dikika, Ethiopia. Nature 443,296-301.

Ambrose, S., 2001. Paleolithic technology and human evolution. Science 291,17481753.

Arbib, M., 2006. A Sentence is to Speech as What is to Action? Cortex 42,507-514.

Arbib, M. A., 2005. From monkey-like action recognition to human language: An evolutionary framework for neurolinguistics. Behavioral and Brain Sciences $28,105-124$

Aron, A. A., T. W. Robbins \& R. A. Poldrack, 2004. Inhibition and the right inferior frontal cortex. Trends in Cognitive Science 8,170-177.

Austin, J. L., 1975. How to do things with words, 2nd edition. Cambridge, MA: Harvard University Press.

Biryukova, E. V., B. Bril, G. Dietrich, A. Roby-Brami, M. A. Kulikov \& P. E. Molchanov. 2005. "The organization of arm kinematic synergies: the case of stone-bead knapping in Khambhat," in Stone knapping: the necessary conditions for a uniquely hominin behaviour. Edited by V. Roux and B. Bril, pp. 73-89. Cambridge: McDonald Institute for Archaeological Research.

Blinkov, S. M. \& I. I. Glezer, 1968. The Human Brain in Figures and Tables: A Quantitative Handbook, English edition. New York: Basic Books.

Bookheimer, S., 2002. Functional MRI of language: new approaches to understanding the cortical organization of semantic processing. Annual Review of Neuroscience 25,151-188.

Buccino, G., F. Binkofski, G. R. Fink, L. Fadiga, L. Fogassi, V. Gallese, R. J. Seitz, K. Zilles, G. Rizzolatti \& H.-J. Freund, 2001. Action observation activates premotor and parietal areas in a somatotopic manner: an fMRI study. European Journal of Neuroscience 13,400-404.

Chase, P. G., 1991. Symbols and Paleolithic artifacts: style, standardization, and the imposition of arbitrary form. Journal of Anthropological Archaeology 10,193214.

Clark, G., 1961. World Prehistory. Cambridge: Cambridge University Press.

Clark, J. D. 1994. "The Acheulian Industrial Complex in Africa and Elsewhere," in Integrative paths to the past: paleoanthropological advances in honor of $F$. Clark Howell. Edited by R. S. Corruccini and R. L. Ciochon, pp. 451-469. Englewood Cliffs: Prentice Hall.

Corballis, M. C., 2003. From mouth to hand: gesture, speech, and the evolution of right handedness. Behavioral and Brain Sciences 26,199-260.

Darwin, C., 2004. The Descent of Man, and Selection in Relation to Sex. London: Penguin Books.

Deacon, T. W., 1997. The symbolic species: The co-evolution of language and the brain. New York: W.W. Norton.

Deacon, T. W. 2003. "Universal grammar and semiotic constraints," in Language evolution. Edited by M. H. Christiansen and S. Kirby, pp. 111-139. Oxford: Oxford University Press.

Decety, J., J. Grezes, N. Costes, D. Perani, M. Jeannerod, E. Procyk, F. Grassi \& F. Fazio, 1997. Brain activity during observation of actions. Influence of action content and subject's strategy. Brain 120,1763-1777.

Dennett, D. C. \& J. C. Haugeland. 1987. "Intentionality," in Oxford companion to the mind. Edited by R. L. Gregory, pp. 383-386. Oxford: Oxford University Press. 
Edwards, S. W. 2001. "A modern knapper's assessment of the technical skills of the Late Acheulean biface workers at Kalambo Falls," in Kalambo Falls prehistoric site, volume 3: the earlier cultures: Middle and Earlier Stone Age. Edited by J. D. Clark, pp. 605-611. Cambridge: Cambridge University Press.

Engels, F. 2003. "The part played by labour in the transition from ape to man," in Philosophy of Technology. Edited by R. C. Scharff and V. Dusek, pp. 71-77. London: Blackwell.

Fagg, A. \& M. A. Arbib, 1998. Modeling parietal-premotor interaction in primate control of grasping. Neural Networks 11,1277-1303.

Falk, D., 2004. Prelinguistic evolution in early hominins: whence motherese? Behavioral and Brain Sciences 27,491-541.

Fiebach, C. J. \& R. I. Schubotz, 2006. Dynamic anticipatory processing of hierarchical sequential events: a common role for Broca's area and ventral premotor cortex across domains? Cortex 42,499-502.

Frey, S. H. \& V. Gerry, 2006. Modulation of neural activity during observational learning of action and their sequential orders. The Journal of Neuroscience 26,13194-13201.

Fuster, J., 2001. The prefrontal cortex - and update: time is of the essence. Neuron 30,319-333.

Gazzaniga, M. S., 2000. Cerebral specialization and interhemispheric communication: does the corpus callosum enable the human condition? Brain 123,1293-1326.

Gentilucci, M., F. Benuzzi, M. Gangitano \& S. Grimaldi, 2001. Grasp with hand and mouth: a kinematic study of healthy subjects. Journal of Neurophysiology 86,1685-1699.

Gibson, K. R. \& T. Ingold, 1993. Tools, language and cognition in human evolution. Cambridge: Cambridge University Press.

Gil-da-Costa, R., A. Martin, M. A. Lopes, M. Munoz, J. D. Fritz \& A. R. Braun, 2006. Species-specific calls activate homologs of Broca's and Wernicke's areas in the macaque. Nature Neuroscience 9,1064-1070.

Goel, V., M. Tierney, L. Sheesley, A. Bartolo, O. Vartanian \& J. Grafman, 2007. Hemispheric specialization in human prefrontal cortex for resolving certain and uncertain inferences. Cerebral Cortex 17,2245-2250.

Graves, P., 1994. Flakes and ladders: What the archaeological record cannot tell us about the origins of language. World Archaeology 26,158-171.

Graziano, M. S. A., L. A. J. Reiss \& C. G. Gross, 1999. A neuronal representation of the location of nearby sounds. Nature 397,428-430.

Greenfield, P., 1998. Language, tools, and brain revisited. Behavioral and Brain Sciences 21,159-163.

Greenfield, P. M., 1991. Language, tools, and brain: The development and evolution of hierarchically organized sequential behavior. Behavioral and Brain Sciences 14,531-595.

Hagoort, P., 2005. On Broca, brain, and binding: a new framework. Trends in Cognitive Science 9,416-423.

Hagoort, P., L. Hald, M. Bastiaansen \& K. M. Petersson, 2004. Integration of word meaning and knowledge in language comprehension. Science 304,438-441.

Hamzei, F., M. Rijntjes, C. Dettmers, V. Glauche, C. Weiller \& C. Buchel, 2003. The human action recognition system and its relationship to Broca's area: an fMRI study. NeuroImage 19,637-644. 
Hartmann, K., G. Goldenberg, M. Daumuller \& J. Hermsdorfer, 2005. It takes the whole brain to make a cup of coffee: the neuropsychology of naturalistic actions involving technical devices. Neuropsychologia 43,625-637.

Hauser, M. D., N. Chomsky \& W. T. Fitch, 2002. The faculty of language: what is it, who has it and how did it evolve? Science 298,1569-1579.

Hickok, G., P. Erhard, J. Kassubek, A. K. Helms-Tillery, S. Naeve-Velguth, J. P. Strupp, P. L. Strick \& K. Ugurbil, 2000. A functional magnetic resonance imaging study of the role of left posterior superior temporal gyrus in speech production: implications for the explanation of conduction aphasia. Neuroscience Letters 287,156-160.

Hihara, S., T. Notoya, M. Tanaka, S. Ichinose, H. Ojima, S. Obayashi, N. Fujii \& A. Iriki, 2006. Extension of corticocortical afferents into the anterior bank of the intraparietal sulcus by tool-use training in adult monkeys. Neuropsychologia 44,2636-2646.

Holloway, R., 1969. Culture: a human domain. Current Anthropology 10,395-412.

Ingold, T. 1996. "Social relations, human ecology, and the evolution of culture: an exploration of concepts and definitions," in Handbook of Human Symbolic Evolution. Edited by A. Lock and C. R. Peters, pp. 178-203. Oxford: Clarendon Press.

Isaac, G. L. 1976. "Plio-Pleistocene artifact assemblages from East Rudolf, Kenya," in Earliest man and environments in the Lake Rudolf basin: stratigraphy, paleoecology, and evolution. Edited by Y. Coppens, F. C. Howell, G. L. Isaac, and R. Leakey, pp. 552-564. Chicago: Univeristy of Chicago Press.

Johnson-Frey, S. H., R. Newman-Norlund \& S. T. Grafton, 2005. A distributed left hemisphere network active during planning of everyday tool use skills. Cerebral Cortex 15,681-95.

Jones, P. R. 1994. "Results of experimental work in relation to the stone industries of Olduvai Gorge," in Olduvai Gorge volume V: Excavations in Beds IV, V and the Masek Beds 1968-1971. Edited by M. D. Leakey and D. Roe, pp. 254-298. Cambridge: Cambridge University Press.

Kan, I. P., J. W. Kable, A. Van Scoyoc, A. Chatterjee \& S. L. Thompson-Schill, 2006. Fractionating the Left Frontal Response to Tools: Dissociable Effects of Motor Experience and Lexical Competition. Journal of Cognitive Neuroscience 18,267-277.

Keijzer, F. A., 1998. Doing without representations which specify what to do. Philosophical Psychology 11,269-302.

Koechlin, E. \& T. Jubault, 2006. Broca's Area and the hierarchical organization of human behavior. Neuron 50,963-974.

Lewis, J. W., 2006. Cortical networks related to human use of tools. Neuroscientist 12,211-231.

Liberman, A. M. \& D. H. Whalen, 2000. On the relation of speech to language. Trends in Cognitive Sciences 4,187-196.

Lieberman, P., 2002. On the nature and evolution of the neural bases of human language. American Journal of Physical Anthropology 45,36-62.

Machin, A. J., R. T. Hosfield \& S. J. Mithen, 2007. Why are some handaxes symmetrical? Testing the influence of handaxe morphology on butchery effectiveness. Journal of Archaeological Science 34,883-893.

MacNeilage, P. F., 1995. Linguistic and manual evolution. Behavioral and Brain Sciences $14,568-569$. 
MacNeilage, P. F., 1998. The frame/content theory of evolution of speech production. Behavioral and Brain Sciences 21,499-546.

MacNeilage, P. F., M. G. Studdert-Kennedy \& B. Lindblom, 1984. Functional precursors to language and its lateralization. American Journal of Physiology Regulatory, Integrative and Comparative Physiology 246,R912-914.

Martin, A. \& L. L. Chao, 2001. Semantic memory and the brain: structure and processes. Current Opinion in Neurobiology 11,194-201.

Martin, R. C., 2003. Language Processing: Functional Organization and Neuroanatomical Basis. Annual Review of Psychology 54,55-89.

Marzke, M. W., N. Toth, K. Schick, S. Reece, B. Steinberg, K. Hunt, R. L. Linscheid $\&$ K. N. An, 1998. EMG study of hand muscle recruitment during hard hammer percussion manufacture of Oldowan tools. American Journal of Physical Anthropology 105,315-332.

Mazza, P. P. A., F. Martini, B. Sala, M. Magi, M. P. Colombini, G. Giachi, F. Landucci, C. Lemorini, F. Modugno \& E. Ribechini, 2006. A new Palaeolithic discovery: tar-hafted stone tools in a European Mid-Pleistocene bone-bearing bed. Journal of Archaeological Science 33,1310-1318.

Mithen, S., 1996. The Prehistory of the Mind: The cognitive origins of art, religion and science. London: Thames and Hudson Ltd.

Nobel, W. \& I. Davidson, 1996. Human evolution, language and mind. Cambridge: Cambridge University Press.

Petrides, M. 2005. "The rostral-caudal axis of cognitive control within lateral frontal cortex," in From monkey brain to human brain: a Fyssen Foundation symposium. Edited by S. Dehaene, J.-R. Duhamel, M. D. Hauser, and G. Rizzolatti, pp. 293-314. Cambridge, MA: The MIT Press.

Poeppel, D., 2003. The analysis of speech in different temporal integration windows: cerebral lateralization as ‘asymmetric sampling in time'. Speech Communication 41,245-255.

Ramnani, N. \& A. M. Owen, 2004. Anterior prefrontal cortex: insights into function from anatomy and neuroimaging. Nature Reviews Neuroscience 5,184-194.

Reynolds, P. C. 1993. "The complementation theory of language and tool use," in Tools, Language and Cognition in Human Evolution. Edited by K. R. Gibson and T. Ingold, pp. 407-428. Cambridge: Cambridge University Press.

Rilling, J. K., 2006. Human and nonhuman primate brains: are they allometrically scaled versions of the same design. Evolutionary Anthropology 15,65-77.

Rilling, J. K., M. F. Glasser, T. M. Preuss, X. Ma, T. Zhao, X. Hu \& T. E. J. Behrens, 2008. The evolution of the arcuate fasciculus revealed with comparative DTI. Nature neuroscience 11,426-8.

Rizzolatti, G. \& M. A. Arbib, 1998. Language within our grasp. Trends in Cognitive Science 21,188-194.

Rizzolatti, G., R. Camarda, L. Fogassi, M. Gentilucci, G. Luppino \& M. Matelli, 1988. Functional organization of inferior area 6 in the macaque monkey. II. Area F5 and the control of distal movements. Experimental brain research 71,491-507.

Rizzolatti, G. \& L. Craighero, 2004. The mirror-neuron system. Annual Review of Neuroscience 27,169-192.

Rizzolatti, G., G. Luppino \& M. Matelli, 1998. The organization of the cortical motor system: new concepts. Electroencephalography and Clinical Neurophysiology 106,283-96. 
Rose, D., 2006. A systematic functional approach to language evolution. Cambridge Archaeological Journal 16,73-96.

Roux, V. \& B. Bril. Editors. 2005. Stone knapping: the necessary conditions for a uniquely hominin behaviour. Cambridge: McDonald Institute for Archaeological Research.

Roux, V., B. Bril \& G. Dietrich, 1995. Skills and learning difficulties involved in stone knapping. World Archaeology 27,63-87.

Santi, A., P. Servos, E. Vatikiotis-Bateson, T. Kuratate \& K. Munhall, 2003. Perceiving Biological Motion: Dissociating Visible Speech from Walking. 15,800-809.

Schick, K. D. \& N. Toth, 1993. Making silent stones speak: human evolution and the dawn of technology. New York: Simon \& Schuster.

Schubotz, R. I. \& D. Y. von Cramon, 2003. Functional-anatomical concepts of human premotor cortex: evidence from fMRI and PET studies. NeuroImage,S120S131.

Schubotz, R. I. \& D. Y. von Cramon, 2004. Sequences of Abstract Nonbiological Stimuli Share Ventral Premotor Cortex with Action Observation and Imagery. The Journal of Neuroscience 24,5467-5474.

Searle, J. R., 1992. The rediscovery of the mind. Cambridge, MA: The MIT Press.

Semaw, S., P. Renne, J. W. K. Harris, C. S. Feibel, R. L. Bernor, N. Fesseha \& K. Mowbray, 1997. 2.5-million-year-old stone tools from Gona, Ethiopia. Nature 385,333-336.

Semaw, S., M. J. Roger, J. Quade, P. R. Renne, R. F. Butler, M. Dominguex-Rodrigo, D. Stout, W. S. Hart, T. Pickering \& S. W. Simpson, 2003. 2.6-Million-yearold stone tools and associated bones from OGS-6 and OGS-7, Gona, Afar, Ethiopia. Journal of Human Evolution 45,169-177.

Skertchly, S. B. J., 1984. The Manufacture of Gunflints. Bloomfield: Museum Restoration Service.

Stout, D., 2002. Skill and cognition in stone tool production: An ethnographic case study from Irian Jaya. Current Anthropology 45,693-722.

Stout, D. \& T. Chaminade, 2007. The evolutionary neuroscience of tool making. Neuropsychologia 45,1091-1100.

Stout, D., N. Toth \& K. Schick. 2006. "Acheulean toolmaking and hominin brain evolution: a pilot study using Positron Emission Tomography," in The Oldowan: case studies into the earliest Stone Age. Edited by N. Toth and K. Schick, pp. 321-331. Gosport, IN: Stone Age Institute Press.

Stout, D., N. Toth, K. Schick, J. Stout \& G. Hutchins, 2000. Stone tool-making and brain activation: Position emission tomography (PET) studies. Journal of Archaeological Science 27,1215-1223.

Stout, D., N. Toth, K. D. Schick \& T. Chaminade, 2008. Neural correlates of Early Stone Age tool-making: technology, language and cognition in human evolution. Philosophical Transactions of the Royal Society of London B 363,1939-1949.

Studdert-Kennedy, M. \& L. Goldstein. 2003. "Launching language: the gestural origins of discrete infinity," in Language evolution. Edited by M. H. Christiansen and S. Kirby, pp. 235-254. Oxford: Oxford University Press.

Thieme, H., 1997. Lower Palaeolithic hunting spears from Germany. Nature 385,80710. 
van Schie, H. T., I. Toni \& H. Bekkering, 2006. Comparable Mechanisms for Action and Language: Neural Systems Behind Intentions, Goals, and Means. Cortex 42,495-498.

Weedman, K. J., 2000. An ethnoarchaeological study of stone scrapers among the Gamo people of southern Ethiopia. unpublished Ph.D. thesis, University of Florida.

Wynn, T., 1995. Handaxe enigmas. World Archaeology 27,10-24.

Wynn, T., 2002. Archaeology and cognitive evolution. Behavioral and Brain Sciences 25,389-438.

Wynn, T. \& W. McGrew, 1989. An ape's view of the Oldowan. Man 24,383-398.

Xu, J., S. Kemeny, G. Park, C. Frattali \& A. Braun, 2005. Language in context: emergent features of word, sentence, and narrative comprehension. NeuroImage 25,1002-1015.

\section{Figures}

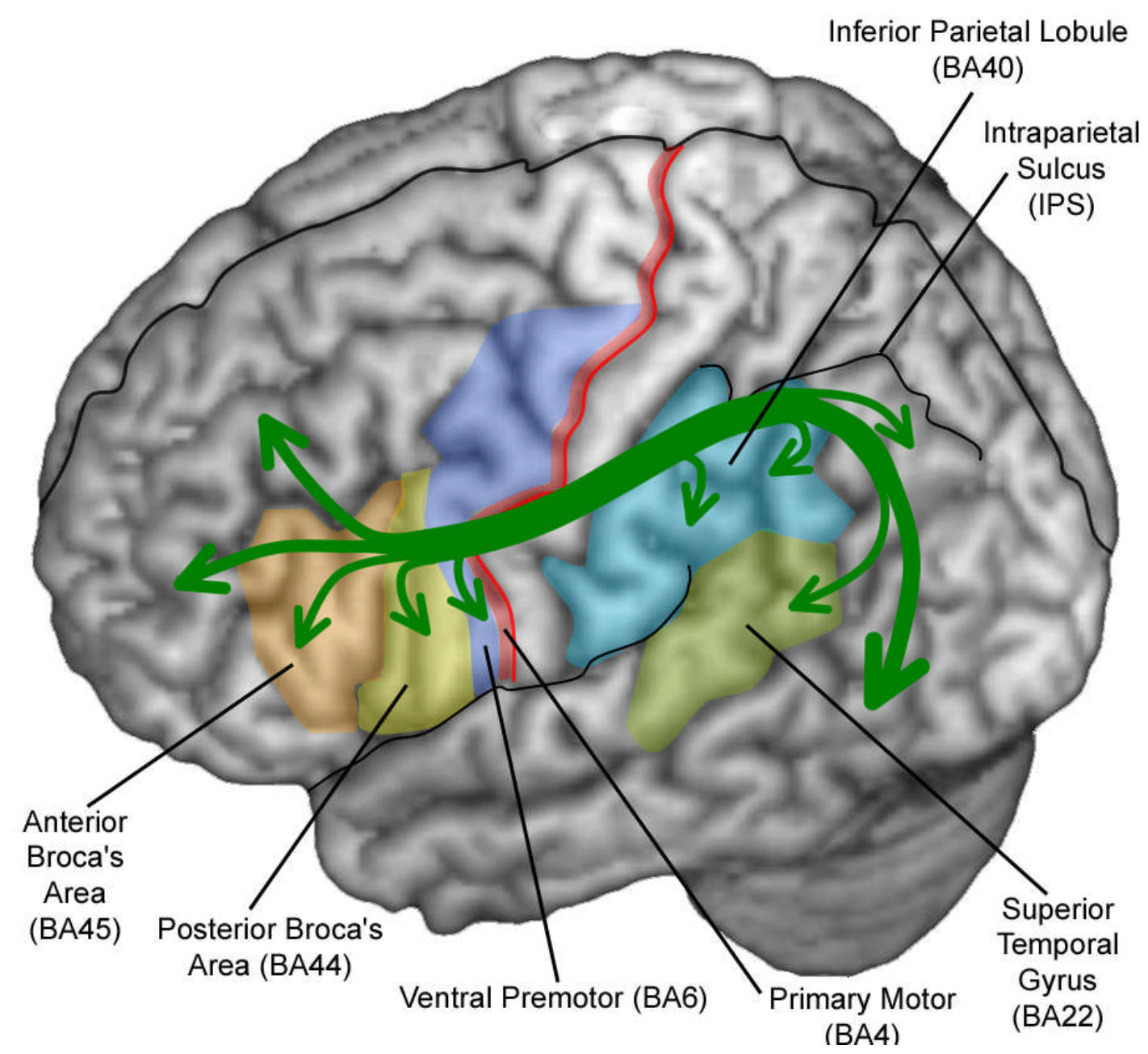

Figure 1. Regions (Brodmann Areas) of frontal, parietal and temporal cortex discussed in the text. Superimposed is the connectivity between frontal and posterior areas via the arcuate fasciculus (after Rilling et al. 2008). 